2007 ASME International Mechanical Engineering Congress \& Exposition

November 12-15, 2007

Seattle, Washington, USA

\title{
IMECE 2007-41853
}

\section{Integrating Wind Turbine Generators (WTG's) with GT-CAES (Compressed Air Energy Storage) stabilizes power delivery with the inherent benefits of Bulk Energy Storage}

\author{
Septimus van der Linden \\ BRULIN Associates LLC \\ 14418 Old Bond Street, Chesterfield, VA 23832, USA \\ Ph. (804) 639-5679. Email: brulinassoc@ comcast.net
}

\begin{abstract}
The installed capacity of WTG's in the US and worldwide, while impressive, suffers from a low capacity factor of $30 \%$ or less due to the variability of wind as the motive force.

Installing larger wind farms to cover the deficiency of capacity results in high costs per delivered $\mathrm{kW} / \mathrm{hr}$. This begs for continued tax incentives to deliver "green" energy to the consumers. The full capability of the WTG is never realized as, at high wind speeds, some of the wind energy has to be "spilled" to maintain a smooth delivery profile.

Technology improvements have not overcome the "wasted" capacity of these modern marvels except where Hydro or Pumped Hydro Storage (PHS) facilities are utilized. The Hydro power station can compensate for wind variability while PHS provides energy storage and delivers power during high demand periods. Wind Energy Storage results in a much higher capacity factor, in effect reducing the cost of delivered $\mathrm{kW} / \mathrm{hrs}$. The problem with this excellent solution is that the USA or the worldwide installation of WTG's do not have such facilities readily available, are expensive to construct and difficult to permit in the USA.

A readily available, cost effective alternative bulkenergy storage technology is ready for deployment
\end{abstract}

throughout most of the continental USA. The GT-CAES concept incorporates a standard production GT with CAES technology and so covers a wide range of power production that can be matched to specific storage sites. During excess wind power production or nighttime wind, this power is used to drive air compressors to pump up or pressurize storage facilities such as salt caverns, deep aquifers (depleted natural gas wells). The stored compressed air is released to an air expander to recover the stored energy. The air to the expansion turbine is pre-heated to 950 to $1050 \mathrm{oF}$ using the Gas Turbine exhaust energy recovered in a Recuperator (HRU). The low exhaust emissions are reduced further with SCR in the HRU.

This paper will examine the early operating CAES concepts vs. the GT-CAES approach and will consider the economics of wind integration for lower costs of electric generation. Wind as a renewable resource would be able to deliver a larger percentage of "green" capacity with the ancillary power benefits of CAES such as Voltage Regulation, load following, spinning reserve, etc., not a feature of WTG's. The patented GT-CAES system is described with examples of small and large installations using proposed projects with integration of Wind Energy. 


\section{Introduction}

The demand for electricity has considerable daily and seasonal variations and the maximum demand may only last for a few hours each year. As a result, some power plants are required to operate for short periods each year - an inefficient use of expensive plants. Without any additional storage above the present $2.5 \%$, mainly PHS, of the installed base load in the USA, base loaded plants are being detrimentally cycled at higher frequency and the situation is further exacerbated by the latest growing demand for renewable energy such as wind energy. In the US, this capacity has now reached in excess of 12,000 MW and the AWEA (American Wind Energy Association) projects up to $30 \mathrm{GW}$ by the year 2020; in Canada the current $2800 \mathrm{MW}$ projects under consideration or contract will grow to $7400 \mathrm{MW}$ to meet energy objectives set for 2015.

The installed capacity of wind turbine generators (WTG's) in North America and worldwide, while impressive in MW capability, suffers from a low capacity factor of $30 \%$ or less in some places due to the variability of wind as the motive force. Installing larger wind farms to cover the deficiency of capacity results in high costs per delivered $\mathrm{kW} / \mathrm{hr}$, especially when tax incentives to deliver "green" energy are discontinued. Storage allows energy production to be de-coupled from its supply, self-generated or purchased. WTG's can only receive energy payments for delivered power, requiring the installation of Gas Turbines or cycling of thermal plants to provide capacity that cannot be delivered by wind. The wind generation variation vs. daily demand requirement illustrated in (Fig. 1)

\section{Dependent Wind Power Needs Fossil Power to Accommodate its Variations}

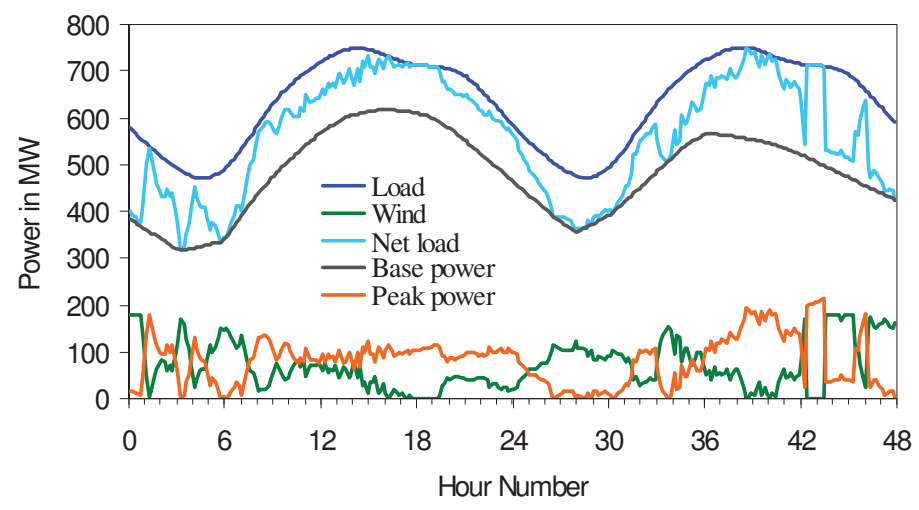

Figure 1 Wind Energy not available during peak
By having large-scale electricity storage capacity available over any time, system planners would need to build only sufficient generating capacity to meet average electrical demand rather than peak demands. The different storage technologies, used in different combinations to suit the specific needs of site, not only in plant output capacity but in response times as well.

Response systems such as Flywheels or Flow Batteries (seconds or milliseconds) can be combined with larger bulk systems (minutes and hours) such as CAES or with SSCAES (small surface storage), 60MW/hr systems or larger $135 \mathrm{MW}$ units in several configurations up to $1000 \mathrm{MW}$ or more, depending on storage cavern volume.

In theory, a typical plant could operate with $40 \%$ less generating capacity than would otherwise be required. This represents considerable financial savings in peaking and intermediate plants. Additional reductions in emissions and capital investment can occur due to the base load generators operating more efficiently at steady state output. The wind energy can be stabilized as well as increased in capacity toward the nameplate rating. Grid instability does lead to regional blackouts. This does open the door for more consideration of Energy Storage. While this is encouraging, there are institutional hurdles to overcome, one of which is the lack of understanding of the value and benefits of Bulk Energy Storage as well as some perceived concepts that simply adding more new power plants and transmission capability will cure blackout problems experienced in recent times in the USA. Storage is probably the better solution!

Storage of electricity (energy) will significantly change the Power Industry for the better: better utilization of resources, better system efficiency, lower emissions, better reliability and security.

Geologically suitable identified sites for bulk energy storage using salt domes, hard rock or aquifers can be readily exploited for 20/30 GW capability by 2020 or sooner, a fact not fully recognized by power entities. Ref [1].

\section{How does a CAES System work?}

The fundamentals of a Gas Turbine are well understood: atmospheric air is compressed to a higher pressure, fuel is added in a combustion chamber and the hot, high pressure combustion gas expands through a turbine that provides both the motive power for the compressor $(60 \%$ 
or more) and the balance of the power (40\% or less) as mechanical energy to drive an electric generator.

In a CAES cycle variation of a standard gas turbine, the compression cycle is separated from the combustion and generation cycle; by using low cost, off-peak or excess electricity, motor driven inter-cooled compressors provide the compressed air held in storage to be released from storage to the modified gas turbine for power generation on demand. In this process, some dramatic changes in the power and economic cycles have occurred. The gas turbine expander absent of its large parasitic load delivers approximately two thirds more power with no increase in fuel consumption, and the required compressed air comes at a much lower cost thus enabling lower cost of electricity generation during high demand cycles from other intermediate load systems such as Gas Fired Thermal or Combined Cycle power plants, or even the lower cost Simple Cycle gas turbine power plants. The illustration (Fig 2) below will help clarify the CAES concept.

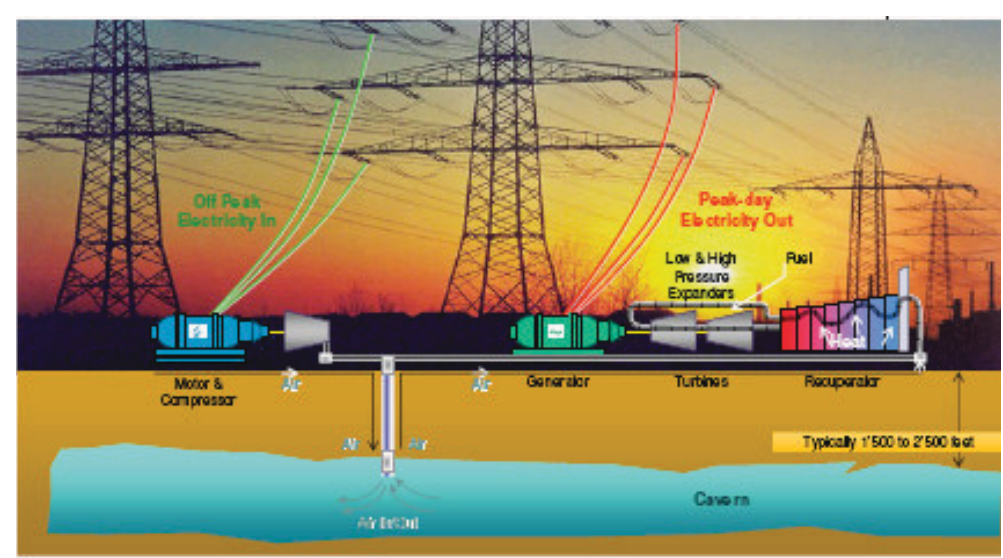

Figure 2 CAES Concept

\section{CAES Technology: Storage Concepts}

Decoupling the Compressor trains from the generating train allows for more flexibility in compression optimization and utilization. Motor driven compressors in $50 \mathrm{MW}$ or lesser increments allow sites and storage volume to best serve the transmission grid needs as well as act as load sinks of 100/200 MW or 300 MW to avoid unnecessary cycling at base loaded plants. The illustration (Fig 3) below captures the decoupling of compression from the power cycle.

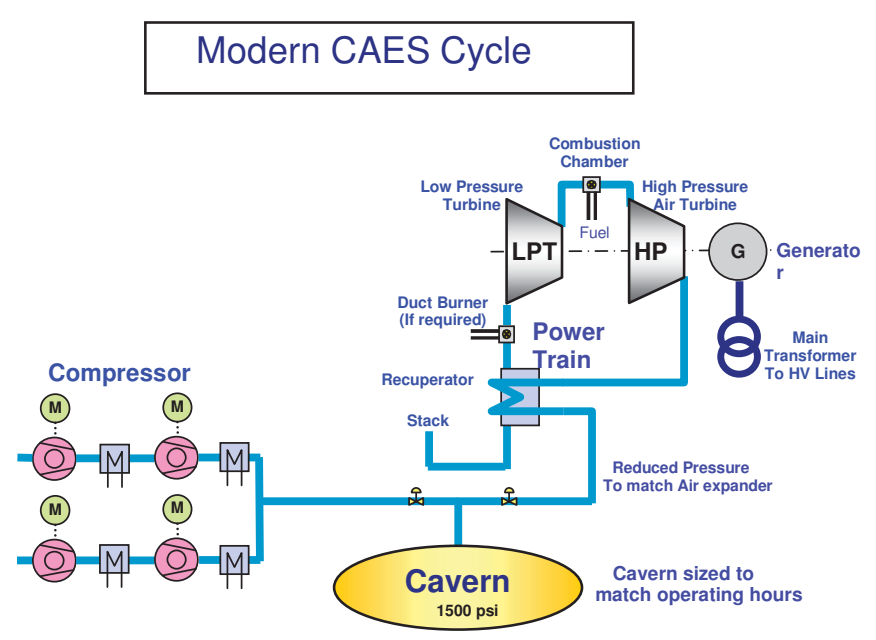

Figure 3 Decoupling the Compression from Power

\section{Applications}

Stored energy integration into the generation-grid system is best illustrated in (Fig. 4) "Energy Storage

Applications on the Grid". This covers a wide field in every aspect of generation-transmission and distribution. The ability of the various technologies to react quickly, converting the stored energy back to electricity readily provides three primary functions:

Energy Management (hours of duration) load leveling or peak period needs; Bridging Power (seconds or minutes duration) assuring continuity of service, contingency reserves or UPS (Uninterruptible Power Supply); and Power Quality \& Reliability (milliseconds o seconds duration) in support of manufacturing facilities, voltage and frequency controls.

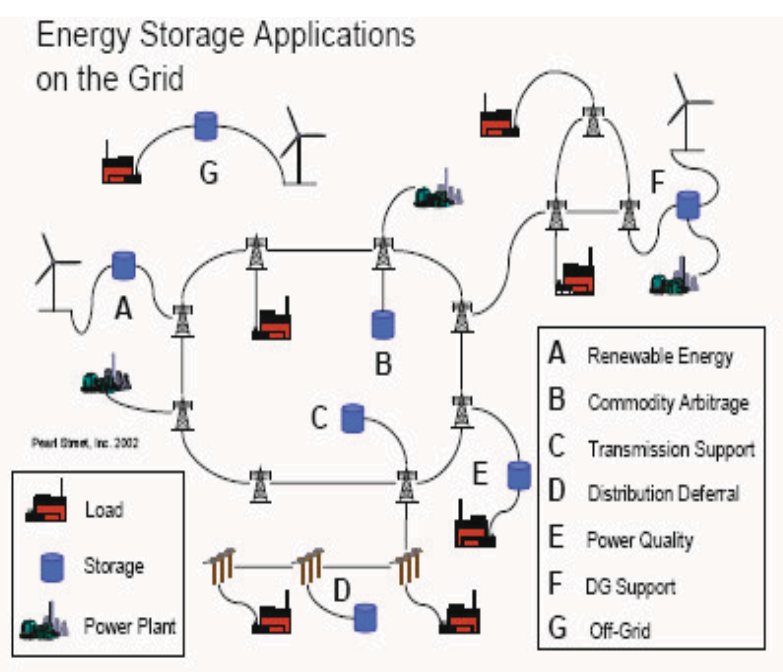

Figure 4 Energy Storage Application on the Grid 


\section{Benefits from Energy Storage}

One of the first benefits would be to fully utilize capital assets, considering that the national average for generation capacity factor is $58 / 60 \%$ and transmission $50 / 52 \%$. Bulk Energy Storage will allow the most efficient units to be fully utilized and allow optimization of the generation mix. Furthermore, it will avoid the use of inefficient units using premium fuels during peak periods. Needle peaks can be readily met with storage as the distribution level or with current installed "peaker" unit capacity.

The market or economic benefits from Energy Storage can be quantified in four major areas of the electricity supply chain, namely: generation, transmission \& distribution, energy services, and renewable energy storage. Projected benefits over a 15 year period for the USA Generation and T\&D system could exceed $\$ 100$ Billion.

\section{Future Prospects (Developments)}

Pumped Hydro has clearly demonstrated the value of Bulk Energy Storage. While these benefits are recognized and utilized, new facilities have languished; projects in development do show promise and opportunities for implementation. The requirement for efficient Clean Coal concepts such as IGCC (gasification) can be enhanced with storage systems to keep the plant at an $80 \%$ or better load factor during the off-peak demand periods and deliver the added stored capacity during high demand.

New concepts are being proposed especially with the growing capacity of wind energy, currently backed by tax incentives. However, at 12,000 MW and projected substantial growth, energy storage and wind energy integration using CAES or Flow Batteries or ganged Flywheels could lead to better economic utilization of a substantial resource operating at below $30 \%$ capacity factor - storage could drive this capacity factor to $65 \%$ or higher.

Concepts outlined in a recent paper at EESAT 2003 Conference [Ref.2] suggested sub-surface storage using large diameter pipes such as typically used for natural gas transportation. Using a storage complex of 2000 meters of pipe, a system that will provide $60 \mathrm{MW} / \mathrm{hrs}$ (15 MW x 4hrs) could enhance power supply at remote wind farms.

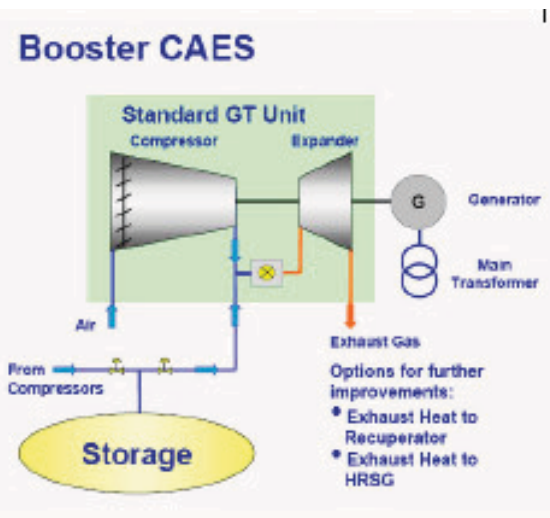

\section{Figure 5 Air Injection (AI) or booster CAES}

This storage pipe concept could be applied to existing GT/CC plants. Increasing the hot day output $20 / 25 \%$ by injecting the stored air into the combustors with or without humidification (Fig 5) By applying the humidification concept, the air supply in a CAES plant could reduce the required storage volume by $30 \%$ or more, or increase the operating hours by $30 \%$ of the specific cavern storage volume. [Ref .3]

In another Hybrid concept proposed, a conventional gas turbine is coupled with storage and a separate unfired air expander for increased flexibility of operation. Using a $180 \mathrm{MW}$ gas turbine, the plant output would exceed 400 MW. (Fig. 6). The advanced technology gas turbine with $38 \%$ efficiency can be operated independently when the cavern air supply has been drawn down. [Ref.4]

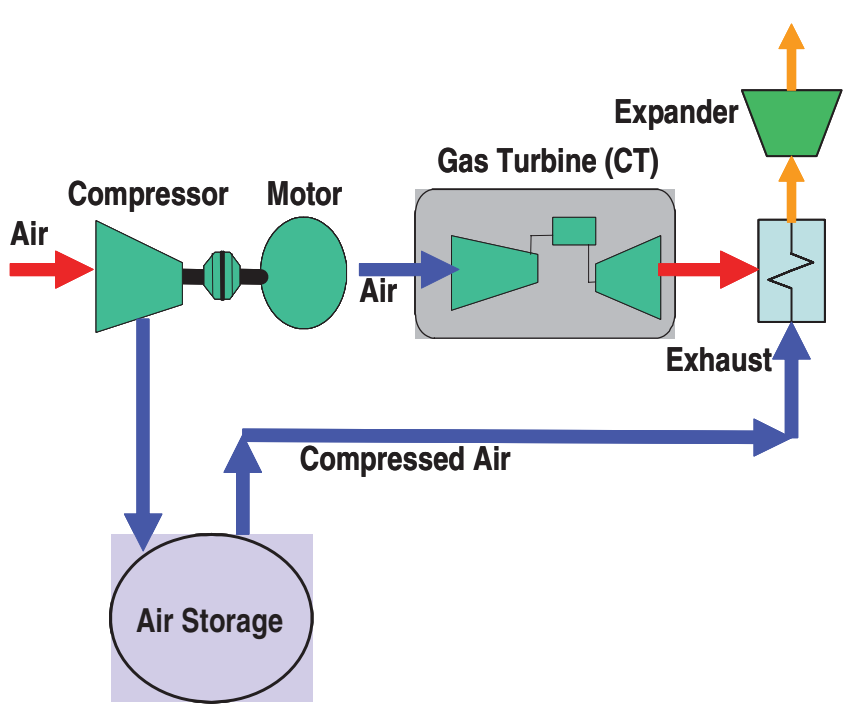

Figure 6 GT-CAES with production GT 
The separate expander (bottoming cycle) allows stored wind "green" energy to remain clean without products of combustion. Systems of 100 MW supported by a 45 MW Gas Turbine is another of several size options using available production gas turbines rather than specially designed Combustion expanders. The first unit in Huntorf Germany (290 MW) and the first unit in McIntosh Alabama (110MW) have high and low pressure sequential combustors, and inline motor/generator driven compressors.

Advanced concepts of Adiabatic Compression \& Expansion, requiring Thermal Energy Storage (TES) have been studied in the US, but more recently in Europe. Such systems would ideally benefit renewable energy systems such as wind, solar and biomass, adding capacity with no premium fuel consumption.

Diabatic CAES plant loses heat from the compression cycle which must be re-generated or added to the compressed air before entering the turbine expansion cycle. Adiabatic CAES will benefit from the thermal energy storage to preheat the stored air which will expand adiabatically through a sliding pressure air turbine, with the added benefit that no $\mathrm{CO} 2$ is generated in the process. Such studies have been completed in Europe with 19 different partners with support and involvement of the European Commission through a research contract. [Ref 5]

Thermal storage devices such as the "Cowper" heat storage devices in glass and metallurgical industries were investigated for suitable thermal storage solutions. The study detailed concept sizes of 30,150 and $300 \mathrm{MW}$ respectively. (Fig.7)

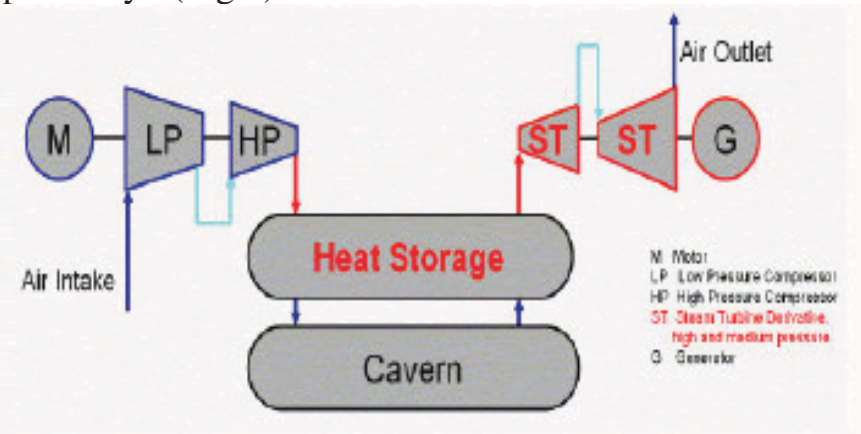

Figure 7 Advanced Adiabatic CAES Concept

Smaller adiabatic systems suitable for isolated Wind Turbine systems where no fuel is added are under development, with utilization of the cold exhaust air to be used for cold storage systems or advanced concepts of "freeze" desalination. [Ref. 6] Such units of $500 \mathrm{~kW}$ and larger are ideal for wind power "smoothing" and distributed generation. The T-CAES $500 \mathrm{~kW}$ system can produce 3600 liters/hr of fresh water from seawater or saline/brackish water.

\section{Projects in Development}

Several large CAES projects with different storage media are in development. Two are fully permitted and of particular note, even when the financial climate for new projects requiring major investments has slowed for such innovative concepts.

\section{Iowa Stored Energy Project (ISEP)}

This project under development by Iowa Association of Municipal Utilities promises to be exciting and innovative. The compressed air will be stored in an underground aquifer and wind energy will be used to compress air in addition to available off-peak power. A separate section of the underground aquifer will be utilized for the storage of natural gas, allowing the CAES facility and other utilities to purchase gas when prices are lower.

The plant configuration is for $270 \mathrm{MW}$ of CAES generating capacity, with $75 \mathrm{MW}$ of wind energy. While wind might be the lowest cost generation system, it is variable and not reliable as a constant source. CAES provides the 'battery' storage for wind energy and makes wind energy a dispatch resource. CAES will expand the role of wind energy in the region generation mix and will operate to follow loads and provide capacity when other generation is unavailable or noneconomic. The underground aquifer near Fort Dodge has the ideal dome structure allowing large volumes of air storage at $870 \mathrm{psig}$ (60 bar.) pressure or more with injection depth of 3000 feet..

Other states such as Illinois also have this potential for Wind \& Storage. "Energy Storage Options for Central Illinois, [Ref.7] but Iowa is in the forefront, possessing a site ideal for a CAES power plant and wind farm. These development plans have a future vision for the value of carbon reduction: adding reliable renewable resources with storage concepts such as CAES. In reality, there are no shortage of potential projects and suitable sites [Ref.1] for Bulk Energy Storage development, there is no energy policy or incentive to implement the advantages and benefits demonstrated by NG Storage or the Pumped Hydro storage now serving the nation's power system. 


\section{Project Markham, Texas}

This 540 MW project in Matagorda County, Texas, developed by Ridge Energy Services, will consist of four 135 MW CAES units with separate LP and HP motor driven compression trains.

The smaller $135 \mathrm{MW}$ units in this project provide a very wide load range from $10 \mathrm{MW}$ minimum per unit and incremental output until all four units provide the system $540 \mathrm{MW}$. The full $540 \mathrm{MW}$ can be delivered in less than 15 minutes. This is a tremendous value to the grid, providing reserve capacity, before cycling of baseloaded plant is required. The variable capacity range would be 840 MW (300 MW Compressor + 540 MW Generator). Nox emissions will be controlled to 5.0 vppm or lower with SCR in the HRU.

This site has Salt Dome cavern storage suitable for high pressure air storage and unique in that natural gas storage is available on the site as well. This is ideal as energy can be arbitraged either as electrons (electricity) or Btu's (natural gas), or a combination of both.

Compression trains totaling $300 \mathrm{MW}$, for the required shorter off-peak charging period, will also act as a very large load sink on the system.

\section{Norton Energy Storage, Ohio}

One of the first potential CAES projects in the USA, developed by Haddington Ventures, Inc., is the huge facility at Norton in Ohio which is permitted for 2700 MW of capacity and as a commercial project when completed will be one of the largest Bulk Energy Storage facilities, including PHS, to be built in the USA. As currently planned, this will consist of $9 \times 300 \mathrm{MW}$ (or larger) nominally rated CAES units supported by an underground storage cavern volume of 338 million cubic feet (120 million cubic meters), 2,200 feet (722 meters) below the surface, originally mined in a limestone formation. This project has languished and has been purchased by Sempra Energy, who are steadily pursuing this opportunity.

Using $200 \mathrm{MW}$ (4 x $50 \mathrm{MW}$ ) compression trains for each 300 MW power train will allow for 16 hours generation by day for 5 days a week. Four units producing $1200 \mathrm{MW}$ could operate for $4 \times 16$ hour days without requiring recharging of the cavern. With more available surface space, cavern volume could support $5400 \mathrm{MW}$ or more for 8 to 10 hours operation, 5 days a week. This cavern was originally permitted for a PHS that would only support a small fraction of that capacity. With this modular approach, the capacity could be added over 5 years allowing full integration in Ohio and the East Central Area Reliability (ECAR) region.

\section{What are the Economics of CAES Systems?}

The best proof of the economics are to look at what Alabama Electric Cooperative (McIntosh CAES Plant $2600 \mathrm{MW} / \mathrm{hr}$ storage) are achieving as well as many different studies that have been conducted comparing CAES with current CCPP as well as IGCC and PC coalfired power plants. Renewable energy such as Wind also demonstrates lower grid costs when integrated with CAES. Site and location specifics will obviously indicate different values and a comparison will have to be made for different regions considering "off-peak" power prices or "spilled" wind energy costs as well as the optimized benefits such as capacity value, transmission value, dispatch value, firming value, shaping value (wind), etc.

There are a number of energy exchanges possible each hour, when WTG'S operate in conjunction with storage systems. There are payments of some sort for each energy exchange, even if the exchange is between two systems that are owned by the same owner.

The correct accounting of the storage system benefits and costs accrue to the storage system, and the wind generators are left in the same situation as when they operate alone.

The optimization and analysis of the energy exchanges and payments are quite complex, and will be very site specific and need to be addressed as a separate topic. CAES power plants like Pumped Hydro have to consider the storage volume and type of storage, such as solution mined caverns in salt domes (as done for NG), hard rock caverns, and aquifers or depleted gas wells. Solution mined caverns are the least costly and would add from $\$ 50$ to $\$ 65 / \mathrm{kW}$ depending on the volume required (kW/hrs) to the overall installed cost $(\$ 600 / 650 / \mathrm{kW})$ which would be comparable or lower to a CCPP installation of equal size. In Texas, the economic impact of CAES could realize approx. \$10 Million per annum, integrating an additional 500MW of Wind just in one region.

From a Pearl Street Executive Briefing Report, “Energy Storage, the Sixth Dimension of the Electricity Value Chain," the following excerpts are provided, indicating the possible economic impact utilizing Bulk Energy Storage:

According to a 1993 DOE Study, the direct impact of energy storage on the US power Industry is estimated at $\$ 57.1$ Billion based on wide spread us of "high density" storage devices. The potential value to day with the increased generation and load requirements is estimated 
at \$174.4 Billion. Improving the operational efficiency of the generation segment holds a potential of $\$ 10.5$ Billion worth of positive economic impact over the next 15 years. By improving the operational efficiency of the transmission segment another \$29.9 Billion potential positive economic gain, is achievable over the next 15 years.

\section{Conclusions and Recommendations}

The current storage concepts are ready for deployment. Storage needs to be implemented in particular for Wind Energy, not just here in the US but I all developing countries. The biggest impact is probably the flexibility op operation. Economic dispatch to meet market needs, absorb excess capacity or large load swings with compression are powerful market tools.

It is possible to improve energy management and obtain better value from bulk power purchase and sales; reduce risks and vulnerabilities from fuel price shocks. In particular, volatility in the US will always be a factor; long term projections show that natural gas prices will continue to rise with increased demand which cannot readily be met from new sources other than LNG imports.

The trend of increased harvesting or wind energy will put further stress on the grid reliability. This is already manifested in Europe where a far greater percentage of its generating base is committed to the variances of wind power production.

Most importantly, Bulk Energy Storage will "buffer" utilities from the lack of spinning reserve and load following capability, a result of many independent Wind Generating Farms installed in the last 5 years and substantial planned capacity. It will remove concerns about power quality and new threats to reliability. CAES as a generating asset has capacity value, as if it were a thermal asset, fully Dispatchable, and a low emissions profile.

Energy Storage provides security, reduces transmission constraints, importantly extends (optimizes) the capabilities of efficient clean coal plants, reduces emissions, and enhances renewable energy. It provides load management, (rapid response) frequency and voltage control, spinning reserve, black start capabilities and supports distributed generation.

\section{References:}

[1] van der Linden, S. "Bulk Energy Storage potential in the USA, current developments and future prospects" Energy 31 (2006) 3446-3457, Science Direct

[2] van der Linden S. CAES for Today's Market. EESAT Conference, San Francisco, CA, April 15-17,2002

[3] .Nakhamkin, M. van der Linden, S. Wolk, R. Patel, M. "New Compressed Air Energy Storage Concept Can Improve the Profitability of Existing Simple Cycle, Combined Cycle, Wind Energy, and Landfill Gas Combustion Turbine-based Power Plants' ASME /IGTI Congress, Vienna ,Austria June ,2004.Ppaer GT2004-54278

[4] Nakhamkin, M. van der Linden, S. ,Integration of a Gas Turbine (GT) with Compressed Air Energy Storage (CAES)provides the best alternative for Mid Range and Daily Cyclic Generation Needs“ ASME/IGTI Congress, Munich, Germany May, 2000. Paper 2000-GT-82

Novel Concept ASME

[5] Bulloch, C. Gatzen, C. et al ."Advanced Adiabatic Compressed Air Energy Storage for the Integration of Wind Energy" Wind Energy Conference, EWEC 2004, November 2004, London U.K

[6] Enis, Dr. B. Lieberman, Dr. P. Rubin, I. van der Linden, S. "Wind Turbine Generator and Compressed Air Energy Storage System for Production of Electrical Power and Cogeneration of Chilled Air for Desalination" ECOS2007 Padua, Italy. June 25-27, 2007.

[7] Makansi, . van der Linden, S .Schien, K. „Energy Storage Options for Central Illinois"-Electrical Energy Storage Applications \& Technology (EESAT) Conference San Francisco, CA. Oct. 27-29, 2003

Illinois 
